\title{
Evaluating the Effectiveness of Peer Education Program on Health Knowledge, Attitudes and Practices
}

\author{
Siti Nur Farhana $\mathrm{H}^{1}$, Shubash Shander $\mathrm{G}^{2}$, Noorlaile $\mathrm{J}^{1}$, Normawati $\mathrm{A}^{1}$, Kamarul Zaman $\mathrm{S}^{1}$, Abu Bakar $\mathrm{R}^{1}$, \\ Suraiya $\mathrm{SM}^{3} \&$ Manimaran $\mathrm{K}^{1}$ \\ ${ }^{1}$ Institute for Health Behavioural Research, Ministry of Health Malaysia, Malaysia \\ ${ }^{2}$ Institute for Public Health, Ministry of Health Malaysia, Malaysia \\ ${ }^{3}$ Health Education Division, Ministry of Health Malaysia, Malaysia \\ Correspondence: Siti Nur Farhana Harun, Institute for Health Behavioural Research, National Institutes of Health, \\ Ministry of Health Malaysia, Setia Alam, 40170 Shah Alam, Selangor. Tel: 60-3-2082-1400. E-mail: \\ farhana@moh.gov.my
}

Received: July 27, 2020 Accepted: October 26, 2020 Online Published: December 8, 2020

doi:10.5539/gjhs.v13n1p74 URL: https://doi.org/10.5539/gjhs.v13n1p74

\begin{abstract}
Kelab Doktor Muda (KDM) which translates as Young Doctors Club was established by the Ministry of Health $(\mathrm{MOH})$ Malaysia to train a group of schoolchildren as educators in assisting their peers to adopt healthy practices. This research aims to assess the effectiveness of KDM as a peer education program to increase the health knowledge of school children, and instil healthy practices among schoolchildren by identifying the difference in the level of knowledge, attitude and health practice between school with KDM (SKDM) and school without KDM (NKDM). This is a nationwide comparative cross-sectional study between SKDM and NKDM. This study was carried out between March 2016 and March 2017. Data were obtained using a guided self-administered questionnaire through survey involving 2588 (1294 SKDM; 1294 NKDM) year 5 (11 years old) schoolchildren from 87 primary schools nationwide. The results revealed a significantly higher overall knowledge score of health practices, knowledge and practice score for No Smoking component, as well as hand hygiene knowledge in SKDM compared to NKDM. Schoolchildren in SKDM also had significantly lower BMI compared to NKDM, directly related to healthy eating, active lifestyle and ideal body weight, 3 of the 6 components in this program. As a conclusion, the program was found to be not only effective in increasing the overall knowledge of health practice among schoolchildren, but also results in a meaningful impact to the health of schoolchildren. Further improvements to the modules however should be undertaken to enable more comprehensive changes on the health practices of schoolchildren.
\end{abstract}

Keywords: peer education program, health education, healthy lifestyle

\section{Introduction}

Health problems among schoolchildren have been one of the highlights in many countries' national health program. The rising of health problems among the schoolchildren such as overweight and obesity are alarming that it becomes one of the top priorities in public health agendas. In 2016, more than 330 million children and adolescents worldwide were either overweight or obese (Abarca-Gómez et al., 2017). Children and adolescent periods are also crucial in providing future health opportunity through prevention and early intervention.

In Malaysia, obesity in children is a serious public health problem and the prevalence has been increasing dramatically over the last two decades (Dea, 2005). Past studies on obesity among schoolchildren showed a consistent prevalence of overweight and obesity between $25 \%$ to 30\% (Institute for Health Behavioural Research, 2011; Institute for Public Health, 2012, 2015). This is likely due to reduced physical activity and changes in diet (Sabramani et al., 2015). Aside from obesity, there are many other health problems among children in Malaysia that needs attention. Prevalence of poor hand hygiene practices was also found to be quite high around $5 \%$ to $25 \%$ (Institute for Public Health, 2012), while dental hygiene was still at unsatisfactory level (Pau, 2012). It is imperative that these two practices be improved at an early stage. In the long run, inculcation of good personal hygiene will reduce the likelihood of developing risk factors to communicable diseases (Hammer, Brainard, \& Hunter, 2018). 
Health problems occur partly due to poor health knowledge that inevitably leads to poor health practices. Thus, instilling health knowledge and enforcing correct attitude are well known to be the key drivers towards good health practices as well as reducing diseases and disabilities (ul Haq et al., 2012). However, instilling healthy practices is often a challenge for many health educators and healthcare workers. This is even more challenging among children and adolescent as they are not aware and may not yet appreciate the long-term benefit of healthy life choices.

Recent studies have shown that intervention programs targeted on schoolchildren through peer-led teaching to be an effective method for improving knowledge, healthy lifestyle practices and attitudes towards health among children (Stock et al., 2007). The unique setting in school is able to help the children in developing positive insight and establishing healthy lifestyle. A study of a peer health education program conducted in a Ugandan Primary School suggested that children did not only learn important lessons about disease prevention, hygiene, sanitation, personal safety, avoiding bad peer relationships, puberty, and nutrition, but they were also changing their behaviour and behaviour of their peers (Falk, Pettet, \& Mpagi, 2016).

In Malaysia, a similar peer-led teaching program has been implemented since 1989. Kelab Doktor Muda (KDM), which translates as Young Doctors Club involves a selection of schoolchildren who were trained as peer educators (Doktor Muda) (Suraiya, Pises, Faizal, Shahnaz, \& Nor Asiah, 2017). This program aims to produce a group of schoolchildren as an agent for promoting good health to their peers, family members and community (Ali et al., 2018). The selected schoolchildren were trained using the KDM Training Module that emphasizes on six (6) health components; Healthy Eating, Hand Hygiene, No Smoking, Active Lifestyle, Dental Health, Ideal Body Weight with the aim to be a mentor or an agent of change towards instilling good knowledge, attitude and health practices among their peers. As of 2019, KDM has been implemented in 3286 number of schools nationwide.

A previous study evaluating the effectiveness of the KDM in primary schools was done in Kelantan, Terengganu and Pahang, focusing on three (3) fundamental areas of health, namely personal, environmental and dental hygiene. The results showed significant differences in knowledge, attitude and health practices between peers in schools implementing the KDM program and schools without KDM (Siti Haslinda M.D, 2005). As a decade passed since the last study, it is high time to re-evaluate the effectiveness of this program and provide the program managers with necessary inputs in improving this program. While the past study only covered three (3) states, this current study covers all the states in Malaysia with far more comprehensive evaluation.

\subsection{Objective}

This research was carried out to assess the effectiveness of KDM, as peer education program in affecting the health knowledge, attitude and practices of the peers. This was carried out by identifying the differences in the level of knowledge, attitude and health practices between schoolchildren in schools with KDM (SKDM) who were not enrolled in KDM (evaluation of the peers), and schoolchildren in schools without KDM (NKDM).

\section{Materials and Methods}

A nationwide comparative cross-sectional study between SKDM and NKDM was carried out between March 2016 and March 2017. A stratified two-stage cluster sampling was applied in this study; the first stage was the selection of school using proportionate sampling and the second stage, selection of the schoolchildren. The schools were selected to ensure equal representation of school from both urban and rural areas between each group. The schoolchildren were matched for gender between the two schools. The data was obtained using guided selfadministered questionnaire. Year 5 schoolchildren were selected for this study to ensure participants had at least one year of exposure to peer educators. Members of KDM were excluded from the study as the aim of this study was to measure the effectiveness of KDM as a peer education program.

\subsection{Sample Size}

Based on previous literature, sample size was determined using two proportions sample size formula with $5 \%$ type 1 error and $80 \%$ power and equal ratio between the groups. Taking into account $20 \%$ non-response the final sample size needed for each group was 1282. (Kim, 2016)

\subsection{Instrument and Pre-Test}

The questionnaire was adapted from The Youth Behavioural Risk Factor Surveillance (YBRFS) (2011), Global School-based Student Health (GSHS) (2012) and covers the scopes in KDM Training Module.

Knowledge on Basic Health

The questions on knowledge consist of 22 items which include questions on healthy eating, hand hygiene, No Smoking, active lifestyle, dental health and ideal body weight. Knowledge questions were in the form of multiple choice. Score zero was given to the wrong answer and one for the right answer. The total score of this section 
ranges from 0 to 22 .

\section{Attitude towards Health}

The questions on attitude consist of 25 items which cover questions on healthy eating, hand hygiene, No Smoking, active lifestyle, dental health and ideal body weight components. The questions were designed as 5 points Likert Scale where the minimum score was 25 and the maximum score was 125 .

\section{Health Practices}

The questions on practice consist of 24 items which include questions on healthy eating, hand hygiene, No Smoking, active lifestyle, dental health and ideal body weight. For the first 22 questions, a score zero was given to the non-compliance answer and score one was given to the compliance answer. The last question had 4 choices, whereby the respondents could choose multiple answers and each compliance answer was scored one. The total score of this section ranges from 0 to 26 .

\subsection{Data Collection and Management}

The selected respondents were gathered in a classroom or school hall where their height and weight were measured by trained research officers to obtain the Body Mass Index (BMI). Briefing regarding this study was given to the respondents prior to answering the questions. The time allocated to answer the questionnaire was between 60 to 90 minutes. Completed questionnaires were reviewed at the field level and data entry was done centrally (Kuala Lumpur Office). The questionnaires were scanned using FormReaderTM software.

\subsection{Data Analysis}

Data were described using frequency, percentage and mean. Data were analysed using independent T-test to determine the mean difference between SKDM and NKDM, while Chi-Square Test was used to determine the association between the outcome variables. The data were analysed using Statistical Program for Social Science (SPSS) software version 23.0 at 0.05 significance level.

\subsection{Ethical Issues}

Ethical approval was obtained from the Medical Research and Ethics Committee, Ministry of Health Malaysia and Educational Planning and Research Division, Ministry of Education Malaysia. Approval from school administrators representing the parents/guardians was obtained as the samples were under the supervision of the school during the study and consent form to participate in the study by schoolchildren was obtained in writing form prior to the study. This study was registered under Malaysia National Medical Research Registry (NMRR) with the identification number NMRR-16-642-30447.

\section{Results}

A total of 87 schools (44 SKDM, 43 NKDM) and 2,588 schoolchildren (1,294 SKDM and 1,294 NKDM) participated in this study. Table 1 showed the demographic characteristics of the respondents, wherein the majority being of Malay ethnicity (84.0\%) and living with both parents $(88.2 \%)$. There was no significant difference in ethnicity $\left(X^{2}=0.474, \mathrm{p}=0.491\right)$ and living arrangement $\left(X^{2}=0.561, \mathrm{p} 0.755\right)$ between schoolchildren in SKDM and NKDM.

Table 1. Demographic Characteristics of Selected Schoolchildren $(n=2,588)$

\begin{tabular}{llllll}
\hline \multirow{2}{*}{ Demographic Characteristics } & & $\mathrm{n}$ & \multicolumn{2}{c}{ Frequency (\%) } & $\mathrm{p}$ value \\
& & & SKDM & NKDM & \\
\hline \multirow{2}{*}{ Ethnicity } & Malay & 2161 & $1087(84.0)$ & $1074(83.0)$ & 0.491 \\
& Others & 427 & $207(16.0)$ & $220(17.0)$ & $1138(87.9)$ \\
\multirow{2}{*}{ Living arrangement } & Both Parents & 2279 & $1141(88.2)$ & $109(8.4)$ & 0.755 \\
& Single Parents & 210 & $101(7.8)$ & $47(3.6)$ & \\
\hline
\end{tabular}

\footnotetext{
${ }^{\top}$ Chi-Square Test.
} 
Table 2. Comparison of Mean Scores for Knowledge, Attitude and Health Practices in SKDM and NKDM schools $(\mathrm{n}=2,588)$

\begin{tabular}{llccc}
\hline & & \multicolumn{2}{c}{ Score (Mean \pm SD) } & \multirow{2}{*}{ p value $^{\dagger}$} \\
\cline { 3 - 4 } Knowledge & Overall & $10.18 \pm 3.06$ & $9.91 \pm 3.05$ & $0.023^{*}$ \\
& Healthy Eating & $3.64 \pm 1.45$ & $3.54 \pm 1.44$ & 0.095 \\
& Hand Hygiene & $1.94 \pm 0.79$ & $1.87 \pm 0.83$ & $0.033^{*}$ \\
& No Smoking & $1.56 \pm 0.94$ & $1.49 \pm 0.94$ & $0.047^{*}$ \\
& Active Lifestyle & $1.34 \pm 0.69$ & $1.32 \pm 0.71$ & 0.500 \\
Dental Health & $0.95 \pm 0.80$ & $0.99 \pm 0.79$ & 0.297 \\
Attitude & Ideal Body Weight & $0.74 \pm 0.80$ & $0.69 \pm 0.80$ & 0.108 \\
\hline Overall & $97.50 \pm 9.09$ & $98.11 \pm 9.81$ & 0.100 \\
Healthy Eating & $24.41 \pm 3.16$ & $24.50 \pm 3.28$ & 0.494 \\
Hand Hygiene & $12.94 \pm 2.09$ & $12.92 \pm 2.13$ & 0.823 \\
No Smoking & $13.00 \pm 2.13$ & $12.94 \pm 2.11$ & 0.442 \\
Active Lifestyle & $16.97 \pm 2.86$ & $17.34 \pm 3.11$ & $0.001^{* *}$ \\
Dental Health & $15.72 \pm 2.45$ & $15.88 \pm 2.50$ & 0.086 \\
& Ideal Body Weight & $17.79 \pm 2.96$ & $17.90 \pm 2.97$ & 0.375 \\
\hline Overall & $16.18 \pm 3.11$ & $15.99 \pm 1.28$ & 0.111 \\
Healthy Eating & $2.56 \pm 1.28$ & $2.55 \pm 1.29$ & 0.765 \\
Hand Hygiene & $3.21 \pm 1.09$ & $3.19 \pm 1.11$ & 0.629 \\
No Smoking & $4.46 \pm 1.02$ & $4.37 \pm 1.00$ & $0.034^{*}$ \\
Active Lifestyle & $1.10 \pm 0.78$ & $1.07 \pm 0.78$ & 0.324 \\
Dental Health & $1.65 \pm 0.53$ & $1.67 \pm 0.54$ & 0.487 \\
Ideal Body Weight & $1.77 \pm 0.95$ & $1.65 \pm 0.96$ & $0.003^{* *}$ \\
\hline
\end{tabular}

${ }^{\dagger}$ Independent T-test.

$* \mathrm{p}<0.05, * * \mathrm{p}<0.01$.

Findings in Table 2 showed significant difference in overall knowledge of health practices between SKDM (10.18 $\pm 3.06)$ and NKDM $(9.91 \pm 3.05 ; \mathrm{t}=2.271, \mathrm{p}=0.023)$. Meanwhile, the overall score of attitude and practice of health practices showed no significant difference between both schools.

Detail analysis showed knowledge score for hand hygiene to be significantly different between SKDM (1.94 \pm $0.79)$ and NKDM $(1.87 \pm 0.83 ; \mathrm{t}=2.137, \mathrm{p}=0.033)$. However, attitude and practice scores for the same component showed no significant difference.

Similarly, the results revealed that SKDM $(1.56 \pm 0.94)$ had significant higher score on knowledge for No Smoking compared to the NKDM $(1.49 \pm 0.94 ; \mathrm{t}=1.987, \mathrm{p}=0.047)$ but having no significant difference in their attitude scores. The No Smoking practice score also was significantly higher among SKDM compared to NKDM ( $\mathrm{p}$ value= 0.034).

In addition, active lifestyle attitude score in SKDM (16.97 \pm 2.86$)$ showed to be significantly lower compared to $\operatorname{NKDM}(17.34 \pm 3.11 ; \mathrm{t}=-3.191, \mathrm{p}=0.001)$, however the practice scores for ideal body weight was significantly higher among SKDM schools ( $\mathrm{p}$ value $=0.003$ ). 
Table 3. Body Mass Index (BMI) of the selected schoolchildren in SKDM and NKDM schools $(n=2,588)$

\begin{tabular}{|c|c|c|c|c|c|}
\hline & & \multirow{2}{*}{$\mathrm{n}$} & \multicolumn{2}{|c|}{ Frequency (Percentage) } & \multirow{2}{*}{$\mathrm{p}$ value } \\
\hline & & & SKDM & NKDM & \\
\hline \multirow{4}{*}{ BMI } & Underweight & $226(8.7)$ & $125(9.7)$ & $101(7.8)$ & \multirow{4}{*}{$0.004 *$} \\
\hline & Normal & $1453(56.1)$ & $747(57.7)$ & $706(54.6)$ & \\
\hline & Overweight & $452(17.5)$ & $227(17.5)$ & $225(17.4)$ & \\
\hline & Obese & 457 (17.7) & $195(15.1)$ & $262(20.2)$ & \\
\hline
\end{tabular}

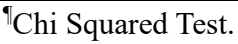

$* \mathrm{p}<0.01$.

The BMI of the schoolchildren showed a significant association between the categories of BMI and the type of school, with $p$ value of 0.004 . A total of $20.2 \%$ of the students in NKDM were obese, with only $15.1 \%$ of students in SKDM being obese. Likewise, only $54.6 \%$ of school children in NKDM had normal BMI, compared to $57.7 \%$ of school children in SKDM. The result was incongruent with Ideal Body Weight practice score result (Table 2) where there was a significant difference in ideal body weight component and showed SKDM has a better score in ideal body weight compared to NKDM. However, we also found that $9.7 \%$ of school children in SKDM were underweight while only $7.8 \%$ of school children in NKDM being in this BMI category.

\section{Discussion}

This study found that the overall knowledge of health practice among schoolchildren in SKDM was significantly higher compared to schoolchildren in NKDM. This proves that this intervention has a positive impact in instilling health knowledge to the schoolchildren, fulfilling the main objective of this peer education program. Good knowledge is an essential component that leads to a positive attitude and subsequently translates into good health practices. (ul Haq et al., 2012). This study found that there was a significantly higher knowledge and practice score for No Smoking component in SKDM compared to NKDM. This finding showed that KDM activities at school and Doktor Muda (peer educator) have helped the peers to understand the downsides of smoking and make a decision to say no to smoking. Reports (Knut-lnge Klepp \& Andrew Halper, 1986) have confirmed that the use of leaders in social groups as a model for school health curriculum has shown to be more effective than relying entirely on teachers in delaying smoking and marijuana use. KDM educates schoolchildren on health and raises awareness of the harmful effects of smoking. Early prevention of smoking among children is known to help prevent future smokers (Krainuwat, 2005). Thus, the intervention program through peer education is crucial in achieving that objective. A school-based smoking prevention program that uses peer leaders has shown to reduce smoking onset by $25-30 \%$, and school plus community programs can reduce smoking onset by $35-40 \%$ by the end of high school (Flay, 2009).

In SKDM, there is an emphasis on practising proper hand hygiene. This was reflected on hand hygiene's knowledge score between both schools, where SKDM scored higher compared to NKDM. Proper handwashing practice is the most important basic hygiene in preventing infectious diseases (Issa, McHenry, Issa, \& Blackwood, 2015). Congruent with a previous study (Young et al., 2017), peer-education was effective at changing knowledge around hygiene including hand hygiene, infection and antibiotic topics as well as a tool to educate young people on the importance of health and hygiene.

The study also revealed that schoolchildren in SKDM had significantly lower attitude score in active lifestyle compared to schoolchildren in NKDM. This, however did not translate into practice, where there was no significant difference between both groups. Thus, KDM needs to be improved to create a significant leap in attitude change towards active lifestyle. Past studies have shown that peer educators provide useful impact towards active lifestyle (Cui, Shah, Yan, Pan, \& Gao, 2012). The vast majority of scientific evidence supports a beneficial role of exercise in achieving bodyweight stability and overall health (Chaput et al., 2011). Despite having lower attitude score in active lifestyle component, it is encouraging to know that SKDM had higher scores in practice of ideal body weight compared to NKDM.

The most convenient and simple to use tool in translating knowledge, attitude and practice scores to more objective measurements would be measuring the schoolchildren BMI. Measuring this would directly akin to healthy eating, active lifestyle and ideal body weight; three of the six components within the KDM program. This study has revealed that schoolchildren in SKDM had significantly different BMI compared to NKDM. There was a higher 
percentage of schoolchildren in the normal BMI category and a lower percentage of schoolchildren in the obese category among schoolchildren in SKDM. This was the most encouraging and objective results of this program. Few other studies have also suggested peer education programs to be an effective means towards preventing obesity (Intan et al., 2016).

In making sure that the necessary health knowledge is properly delivered to the schoolchildren and being translated into attitude and practice, attention should be given on the dissemination of the health messages from the members of KDM to the peers to further improve the program. The discouraging results of knowledge, attitude and practice findings of SKDM in this study could be due to the low confidence in delivering the health messages by DM to the peers (Pises, Ha, Sm, S, \& Suriya, 2012) and also the lack of interest by peers in learning on health, subsequently resulting to the poor feedback (Suraiya et al., 2017) (Muhamad et al., 2017). The magnitude of the difference was found to be small and could also be due to multiple factors such as the accessibility of health knowledge to the school children via multiple sources of health information (Al-darwish, 2015) and existing school programs besides the KDM (Christian et al., 2015).

The program manager can use the result of this study to improve the KDM training module and update the content based on public health needs. Modules that did not show an increase in knowledge and practice may need to be revised, and also made suitable according to the current times. Analysing the sub-components of the program, alerts us that there is a need to fine tune and improve the approach in the other components of this program. This study also lends supports that the program should be expanded further to more schools within Malaysia as school-based interventions have the potential to improve the health and well-being of students and their communities especially by focusing on both individual and environmental determinants of health (Mukamana \& Johri, 2016).

\subsection{Limitation}

The strength of this study lies in the comprehensive enrolment from schools nationwide, at the same time providing a detailed analysis of the findings compared to the previous study. However, this study is not without limitation. By adopting a cross-sectional study, there is limited information available to measure the actual effectiveness of the program. The changes of health knowledge to practice for example could not be measured through a cross-sectional study. Moreover, this study only includes year 5 schoolchildren in primary school, in which the decision-making process is still quite limited. Majority of studies on peer education program measure the effectiveness from the perspective of adolescents. Hence, future study should give focus on different study type such as a cohort study.

There are more components in the knowledge module that are significant compared to attitude and practices. One of the things we must consider is the time of evaluation between the peer education program been introduced to the school children and the evaluation of its effectiveness. 1 to 2 years period of evaluation might be too early to result in inculcating changes in attitude and practice. An assessment after a longer period is thus necessary to detect the changes in attitude and practice and also determine the long term impact of this program.

\section{Conclusion}

As a conclusion, the Doktor Muda peer education program was found to be effective in increasing the overall knowledge of health practice among schoolchildren. The program also results in a meaningful impact to the health of schoolchildren, as schoolchildren in SKDM also had significantly lower BMI compared to NKDM, directly related to healthy eating, active lifestyle and ideal body weight, 3 of the 6 components in this program. Even though not all components of this program have significant results, there were still evidence of encouraging impacts shown by KDM towards schoolchildren's health behaviour. Further improvements to the modules however should be undertaken to enable more comprehensive changes on the health practices of schoolchildren, which is hoped that they will carry on to adulthood.

\section{Funding}

This work was supported by a grant of Ministry of Health Malaysia.

\section{Acknowledgements}

Authors would like to thank the Director General of Health, Malaysia for permission to publish this paper. We also thank all those who were involved in this study for their contribution and commitment throughout the study.

\section{Competing Interests Statement}

The authors declare that there are no competing or potential conflicts of interest. 


\section{References}

Abarca-Gómez, L., Abdeen, Z. A., Hamid, Z. A., Abu-Rmeileh, N. M., Acosta-Cazares, B., Acuin, C., ... \& Agyemang, C. (2017). Articles Worldwide trends in body-mass index, underweight, overweight, and obesity from 1975 to 2016 : a pooled analysis of 2416 population-based measurement studies in 1289 million children, adolescents, and adults. The Lancet, 2627-2642. https://doi.org/10.1016/S0140-6736(17)32129-3

Al-Darwish, M. S., Abuhassna, M., \& Al-Thomairy, S. A. (2015). Oral Health Knowledge and Sources of Oral Health Information among School Children in Qatar. Journal of Dental Health, Oral Disorders \& Therapy, 2. https://doi: 10.15406/jdhodt.2015.02.00049

Ali, H. A. M., Ishak, I., Ramli, N. A., Manan, Y. S. A., Samsudin, S., \& Mohamed, D. M. S. (2018). How Kelab Doktor Muda (Young Doctor Club) for Special Needs in High- Performance School SK Seri Biram, Pekan, Pahang Manages to Develop Self-Confidence among Special Needs Students Towards Health. International Journal for Studies on Children, Women, Elderly And Disabled, 4.

Chaput, J. P., Klingenberg, L., Rosenkilde, M., Gilbert, J. A., Tremblay, A., \& Sjödin, A. (2011). Physical activity plays an important role in body weight regulation. Journal of Obesity, 2011. https://doi.org/10.1155/2011/360257

Christian, D., Todd, C., Davies, H., Rance, J., Stratton, G., Rapport, F., \& Brophy, S. (2015). Community led active schools programme (CLASP) exploring the implementation of health interventions in primary schools: headteachers' perspectives. BMC public health, 15(1), 238. https://doi.org/10.1186/s12889-015-1557-0

Cui, Z., Shah, S., Yan, L., Pan, Y., Gao, A., Shi, X., ... \& Dibley, M. J. (2012). Effect of a school-based peer education intervention on physical activity and sedentary behaviour in Chinese adolescents: a pilot study. BMJ open, 2(3). https://doi.org/10.1136/bmjopen-2011-000721

O'Dea, J. A. (2005). Prevention of child obesity:'First, do no harm'. Health education research, 20(2), 259-265. https://doi.org/10.1093/her/cyg116

Falk, D. S., Pettet, K., \& Mpagi, C. (2016). A Peer-to-Peer Health Education Program for Vulnerable Children in Uganda. Journal of Education and Training Studies, 4(3), 161-166. https://doi.org/10.11114/jets.v4i3.1294

Flay, B. R. (2009). School-based smoking prevention programs with the promise of long-term effects. Tobacco Induced Diseases, 5(1), 29-35. https://doi.org/10.1186/1617-9625-5-6

Hammer, C. C., Brainard, J., \& Hunter, P. R. (2018). Risk factors and risk factor cascades for communicable disease outbreaks in complex humanitarian emergencies: a qualitative systematic review. BMJ Global Health, 3(4), e000647. https://doi.org/10.1136/bmjgh-2017-000647

Institute for Health Behavioural Research. (2011). The Youth Behavior Risk Factor Surveillance (YBRFSS). Kuala Lumpur: Institute for Health Behavioural Research, Ministry of Health Malaysia.

Institute for Public Health. (2012). The National Health and Morbidity Survey: Malaysia School Based Nutrition Survey 2012. Kuala Lumpur: Institute for Public Health, Ministry of Health Malaysia.

Institute for Public Health. (2015). National Health and Morbidity Survey 2015. Vol. II: Non-Communicable Diseases, Risk Factors \& Other Health Problems. In Ministry of Health (Vol. 2). https://doi.org/10.1017/CBO9781107415324.004

Intan, S., Sharif, Z., Chin, Y. S., Nasir, M., Taib, M., \& Shariff, Z. M. (2016). School-based intervention to prevent overweight and disordered eating in secondary school Malaysian adolescents : a study protocol. BMC Public Health, 1-12. https://doi.org/10.1186/s12889-016-3773-7

Issa, M., McHenry, M., Issa, A. A., \& Blackwood, R. A. (2015). Access to safe water and personal hygiene practices in the kulandia refugee camp (jerusalem). Infectious Disease Reports, 7(4), 81-86. https://doi.org/10.4081/idr.2015.6040

Kim, H.-Y. (2016). Statistical notes for clinical researchers: Sample size calculation 3. Comparison of several means using one-way ANOVA. Restorative Dentistry \& Endodontics, 41(3), 231. https://doi.org/10.5395/rde.2016.41.3.231

Knut-lnge Klepp, \& Andrew Halper, C. L. P. (1986). The efficacy of peer leaders in drug abuse prevention. Journal of School Health, 56(9). https://doi.org/10.1002/9780470975084.ch2

Krainuwat, K. (2005). Smoking initiation prevention among youths: implications for community health nursing practice. Journal of community health nursing, 22(4), 195-204.https://doi.org/10.1207/s15327655jchn2204 
Muhamad, N. A., Busu, P., Hum, W. L., Mustapha, N., Ali, S., Murad, S., ... \& Mohamed, S. S. (2017). Doktor Muda Competencies: Self-efficacy and Hand Washing Demonstration Skill among School Children in Malaysia. Global Journal of Health Science, 9(12), 47. https://doi.org/10.5539/gjhs.v9n12p47

Mukamana, O., \& Johri, M. (2016). What is known about school-based interventions for health promotion and their impact in developing countries? A scoping review of the literature. Health Education Research, 31(5), 587-602. https://doi.org/10.1093/her/cyw040

Pau, A. K. H. (2012). Challenges in dental public health-An overview. International e-Journal of Science, Medicine and Education, 6(supp1), S106-S112.

Pises, B., Ha, H., Sm, S., S, K. Z., \& Suriya, H. (2012). Apa Doktor Muda sampaikan dan rakan sebaya inginkan? Journal of Health Management.

Sabramani, V. A. L., Idris, I. B., Sutan, R., Isa, Z. M., Buang, S. N., \& Ghazi, H. F. (2015). Managing obesity in malaysian schools: Are we doing the right strategies? Malaysian Journal of Public Health Medicine, 15(2), $75-83$.

Siti Haslinda, M. D. (2005). Kajian Keberkesanan Program Doktor Muda di Sekolah Rendah Negeri Kelantan, Terengganu dan Pahang. Kuala Lumpur: Bahagian Pendidikan Kesihatan, Kementerian Kesihatan Malaysia.

Stock, S., Miranda, C., Evans, S., Plessis, S., Ridley, J., Yeh, S., \& Chanoine, J. P. (2007). Healthy buddies: A novel, peer-led health promotion program for the prevention of obesity and eating disorders in children in elementary school. Pediatrics, 120(4). https://doi.org/10.1542/peds.2006-3003

Suraiya, S., Pises, B., Faizal, B., Shahnaz, M., \& Nor Asiah, M. (2017). School Children as Health Agent: An Explorative Study on Peers' Perspectives. Global Journal of Health Science, 9(5), 1. https://doi.org/10.5539/gjhs.v9n5p1

ul Haq, N., Hassali, M. A., Shafie, A. A., Saleem, F., Farooqui, M., \& Aljadhey, H. (2012). A cross sectional assessment of knowledge, attitude and practice towards Hepatitis B among healthy population of Quetta, Pakistan. BMC Public Health, 12(1), 692. https://doi.org/10.1186/1471-2458-12-692

Young, V. L., Cole, A., Lecky, D. M., Fettis, D., Pritchard, B., Verlander, N. Q., ... McNulty, C. A. M. (2017). A mixed-method evaluation of peer-education workshops for school-aged children to teach about antibiotics, microbes and hygiene. Journal of Antimicrobial Chemotherapy, 72(7), 2119-2126. https://doi.org/10.1093/jac/dkx083

\section{Copyrights}

Copyright for this article is retained by the author(s), with first publication rights granted to the journal.

This is an open-access article distributed under the terms and conditions of the Creative Commons Attribution license (http://creativecommons.org/licenses/by/4.0/). 